\title{
Commentary and Opinions: The Utilization of Social Media by Medical Residency Programs During COVID-19 Pandemic and Beyond
}

\author{
Leilynaz Malekafzali ${ }^{1}$, Chaocheng Liu $^{2}$ \\ ${ }^{1}$ BSc, MD Candidate 2023, University of British Columbia, Vancouver, Canada \\ ${ }^{2} \mathrm{MD}$, Department of Dermatology and Skin Science, University of British Columbia, Vancouver, Canada \\ Correspondence: Chaocheng Liu, MD, Department of Dermatology and Skin Science, University of British Columbia, \\ Vancouver, Canada.
}

Received: August 22, 2021

doi:10.11114/jets.v10i2.5443
Accepted: December 24, $2021 \quad$ Online Published: January 5, 2022

URL: https://doi.org/10.11114/jets.v10i2.5443

\begin{abstract}
As a result of COVID-19 pandemic, medical training has been greatly impacted globally. In Canada, out-of-province visiting clinical electives were cancelled. In addition, the Canadian Resident Matching Service (CaRMS) interviews were transitioned to being virtual since 2020. As residency programs are exploring new ways to overcome the challenges of elective cancellation, there has been a surge of residency program social media accounts on Instagram, Twitter, and Facebook. Social media serves as a platform for residency programs to promote themselves in addition to posting interactive educational materials. Moreover, social media residency accounts provide a platform for medical students to learn about the programs and network virtually with fellow applicants, residents, program directors, and faculty members. Overall, social media is becoming a popular and valuable tool for residency programs to connect with the applicants during COVID-19 pandemic and beyond. Among the different social media platforms, Instagram seems to be more appealing to both residency programs and the graduating medical students. We report our observations regarding selected Canadian residency program Instagram accounts. To maximize the success of using social media, it is important for the residency programs to consider the attitudes of applicants towards the residency social media accounts. Future studies are needed to assess the effectiveness of the Canadian residency program social media accounts for the final year students applying for these programs.
\end{abstract}

Keywords: social media, Instagram, medical residency matching, COVID-19 pandemic, Canadian Resident Matching Service (CaRMS)

Medical training has been greatly impacted by COVID-19 pandemic globally. Prior to this year, final year medical students had the option of completing out-of-province visiting clinical electives to explore different residency programs across Canada. For the 2020-2021 application cycle, students lost such opportunities due to nationwide cancellation of all the out-of-province electives. Additionally, the ability of out-of-province residency programs to evaluate the clinical performance of applicants has also become limited. The Canadian Resident Matching Service (CaRMS) interviews were also transitioned to being virtual, which further restricted the in-person interaction between the applicants and residency programs.

As residency programs are exploring new ways to overcome the challenges of elective cancellation, there has been a surge of residency program social media accounts on Instagram, Twitter, and Facebook (Fang et al., 2021; DeAtkine et al., 2020). For the residency programs, social media serves as a platform to promote themselves by posting about residents' biographies, programs' virtual open-house events, facilities, and research opportunities (DeAtkine et al., 2020). In addition, programs can post interactive educational materials on their social media accounts (Ahmadmehrabi, Xie, Ward, Bryson, \& Byrne, 2021). From the medical student perspective, social media residency accounts are beneficial as they allow them to explore different aspects of the programs in a new way (Ahmadmehrabi, Xie, Ward, Bryson, \& Byrne, 2021). Moreover, students have a chance to network virtually with their fellow applicants, residents and program directors through social media given the social distancing measures in place for the COVID-19 pandemic (Ahmadmehrabi, Xie, Ward, Bryson, \& Byrne, 2021; Fang et al., 2021). Another advantage of virtual experiences is that they reduce financial barriers and geographical limitations for students (Fang et al., 202)

To maximize the success of using social media, it is important for the residency programs to consider the attitudes of 
applicants towards the residency social media accounts. It has been shown that regular and frequent posts can lead to a higher number of followers (Steele, Galarza-Paez, Aguilo-Seara, \& David, 2020). In terms of the content, applicants are mostly interested in seeing information about the programs, residents' lives, and educational materials on the accounts (Steele, Galarza-Paez, Aguilo-Seara, \& David, 2020). Recent research on the topic of utilization of Instagram by dermatology residency programs in the era of COVID-19 found that posts related to "resident spotlights" received the most engagement (Schwartzman, Qureshi, \& Friedman, 2021). The content of these posts includes photos and information about residents, such as why they chose their respective programs, their interests, and their plans following graduation (Schwartzman, Qureshi, \& Friedman, 2021). However, when it comes to applying and preparing for residency interviews, the applicants may prefer accessing information from the program websites and interpersonal resources including mentors, faculty members, and residents over social media accounts (Steele, Galarza-Paez, Aguilo-Seara, \& David, 2020).

There are some potential concerns when it comes to social media accounts for the residency programs. There are no clear guidelines about how applicants should engage with the social media accounts (Rohde, White, \& Yoo, 2020). Some applicants may unknowingly feel worried that their own social media content be screened by programs and be viewed as potentially unprofessional, impacting their application rank (Rohde, White, \& Yoo, 2020). In the future, residency programs should consider informing applicants about who is running their social media accounts including resident or program directors, and their expectations of the applicant's engagement with their accounts (Rohde, White, \& Yoo, 2020).

Among the different social media platforms, Instagram seems to be more appealing to both residency programs and the graduating medical students, given the visual-based content of the Instagram posts (DeAtkine et al., 2020; Steele, Galarza-Paez, Aguilo-Seara, \& David, 2020). Additionally, Instagram Stories provide real-time updates and interactive tools to allow followers to participate in polls or ask questions. We reviewed Canadian residency program Instagram accounts. Selected Instagram accounts with diverse contents include but are not limited to UBC Vancouver Emergency Medicine Residency (@ubcvanem), MacMaster Ob/Gyn Residency (@macobgynresidency), UOttawa Dermatology (@ottawadermatology), and UBC Orthopaedic Surgery (@ubcorthopaedicresidency). All these accounts along with many others were made in 2020, at the onset of COVID-19 pandemic. They feature the residency programs by showcasing the residents' biographies, faculty members, program information and updates, research opportunities, and educational content. Also, the programs' websites and information about the Instagram account administrators are included in the accounts allowing the students to easily access the desired information.

Overall, social media is becoming a popular and valuable tool for residency programs to connect with the applicants during COVID-19 pandemic and beyond. Moving forward, the residency programs should consider having a clear plan for managing the content on their social media accounts, including information about the programs, residents' biographies, and educational materials. Additionally, the programs should gather feedback from the students to understand and address the needs of future applicants given the out-of-province electives are still on-hold for the 2021-2022 application cycle. Furthermore, the effectiveness of these virtual experiences for the students remains unclear due to a lack of studies. Future studies are needed to assess the effectiveness of the Canadian residency program social media accounts for the final year students applying for these programs.

\section{References}

Ahmadmehrabi, S., Xie, D. X., Ward, B. K., Bryson, P. C., \& Byrne, P. (2021). OHNS Residency Program and Applicant Social Media Presence During the COVID-19 Pandemic. Annals of Otology, Rhinology \& Laryngology, 130(8), 961-965. https://doi.org/10.1177/0003489420987977

DeAtkine, A. B., Grayson, J. W., Singh, N. P., Nocera, A. P., Rais-Bahrami, S., \& Greene, B. J. (2020). \#ENT: Otolaryngology Residency Programs Create Social Media Platforms to Connect With Applicants During COVID-19 Pandemic. Ear, Nose \& Throat Journal. https://doi.org/10.1177/0145561320983205

Fang, H. A., Boudreau, H., Khan, S., Singh, N. P., Rais-Bahrami, S., King, T. W., .. \& Chen, H. (2021). An evaluation of social media utilization by general surgery programs in the COVID-19 era. The American Journal of Surgery, 222(5), 937-943. https://doi.org/10.1016/j.amjsurg.2021.04.014

Rohde, S. C., White, E. M., \& Yoo, P. S. (2020). Residency Program Use of Social Media in the COVID-19 Era: An Applicant's Perspective. Journal of Surgical Education, 78(4), 1066-1068. https://doi.org/10.1016/j.jsurg.2020.12.011

Schwartzman, G., Qureshi, A., \& Friedman, A. J. (2021). Utilization of Instagram by Dermatology Residency programs in the Era of COVI-19. Journal of the American Academy of Dermatology, 85(1), 204-206. https://doi.org/10.1016/j.jaad.2021.03.078 
Steele, T. N., Galarza-Paez, L., Aguilo-Seara, G., \& David, L. R. (2021) Social media impact in the match: A survey of current trends in the United States. Archives of Plastic Surgery, 48(1), 107-113. https://doi.org/10.5999/aps.2020.00836

\section{Copyrights}

Copyright for this article is retained by the author(s), with first publication rights granted to the journal.

This is an open-access article distributed under the terms and conditions of the Creative Commons Attribution license which permits unrestricted use, distribution, and reproduction in any medium, provided the original work is properly cited. 